\title{
Investigating Factors Affecting EFL Teachers' Choice in Integrating Authentic E-Materials
}

\author{
Fitria Rahmawati ${ }^{1, *}$ Althof Shobrun Jamil ${ }^{2}$ \\ ${ }^{1}$ Universitas Muhammadiyah Yogyakarta \\ ${ }^{2}$ Universitas Muhammadiyah Yogyakarta \\ *Email: fitriarahmawati@umy.ac.id
}

\begin{abstract}
Exposing EFL students to authentic materials has been considered a valuable learning experience as it can expose students to the target language. This study explores the EFL teachers' practices using authentic materials, especially in their e-learning courses, including 1) identifying the kinds of the authentic e-materials and 2) investigating the teachers' consideration in using the authentic e-materials. This study's setting was at the English Language Education Department (ELED) of one Indonesian private university. The descriptive case study was adopted as the research design. The data were gathered by interviewing four teachers and observing the teaching materials used in the e-learning platforms. The findings indicated that the teacher-participants used several types of authentic e-materials categorized into three: audio, visual, and audiovisual or multimedia materials. The findings also revealed the teachers' considerations in using the authentic e-materials in e-learning. The teachers considered three main factors in integrating authentic e-materials, including the materials, the content, and the preparation time. Also, the teacher-participants indicated various beliefs on exposing their students to authentic e-materials. However, they agreed that providing various authentic materials into EFL learning, especially into the e-learning practices, was considered viable and meaningful.
\end{abstract}

Keywords: Learning material, authentic material, electronic materials, e-learning

\section{INTRODUCTION}

The use of e-learning technology offers several advantages for both teachers and students. Anderson [1] argued that e-learning helps teachers provide a real-time learning experience, increasing access, eliminating time, place, and social barriers, reducing cost, increasing transparency, engagement, and lifetime learning assistance. By using e-learning technologies, teachers can increase the quality of their teaching experiences into more efficient, effective, situational, and supportive. Also, Kanuka [2] believed that the impact of e-learning is felt by teachers who teach using e-learning technology, such as effectively responding to accelerate global competition and increasing the quality of learning experiences. E-learning technology allows teachers to remove situational barriers and create more meaningful learning activities and tasks into their teaching practices. E-learning technology also provided unlimited benefits for students. Yucel [3] asserted that the advantage of elearning for students is that they allow students to decide their learning style, time, and pace. It infers that students can decide and practice their preferred learning style, learning materials, lesson topic, objective, proficiency and skill. Thus, e-learning technology has long been considered integrated into the educational setting, especially in the higher education context.

E-learning technology plays a significant role in education, yet, there are considerations that teachers need to take into account when they want to integrate elearning technology. One of the considerations is the teaching material. Teachers must consider whether the material's design is appropriate to engage the students and the delivery methods that allow for flexible access. Djono [4] stated that it is significant for teachers to develop the teaching materials, as tailored teaching materials will considerably enhance the students' learning efficiency and adequacy. He further stated that the teaching materials serve as a basis for teachers responsible for instructional tasks and the substances of knowledge being learned.

Electronic material belongs to the teaching materials used in the e-learning context. While implementing elearning, teachers need to consider the electronic materials they use. Rosset [5] described that online 
learning provides numerous opportunities. It takes commitment and resources and needs to be conducted properly and means the materials should be appropriately designed focusing on the students and the learning. Also, sufficient assistance should be given (as cited in Anderson, 2008, p.18). Some of the electronic materials are authentic, for example, news, advertisement, audios, and videos. These authentic materials could be used as resources for learning. Yucel [3] explained that authentic materials in the form of electronic refer to an application that is accessible for teachers and students. He added that many proof exams e-Examination administer the examples of the application, e-test using various available online test tools software, e-books and etelevision, and e-sound book application facilitating the students with hearing difficulties to be able to comprehend the contents of the textbook. Therefore, these materials are appropriate for e-learning courses because they are useful in enhancing students' understanding.

Teachers must develop their teaching materials. Especially for e-learning courses, the teaching materials are in the form of electronic materials (e-materials). Moreover, some of them are authentic materials which are embedded in the e-learning course (for further mention in this research, the researchers use the term 'authentic electronic materials' and it is abbreviated into 'authentic e-materials'). The selection of those authentic e-materials is vital for their lesson and should be based on students' needs. Investigating the teachers' practices in integrating authentic e-materials in the e-learning course is worth conducting. Knowing various types of authentic electronic materials enables teachers to select and develop appropriate authentic electronic learning materials carefully. Besides, the considerations before delivering the materials and strategies when delivering the materials are significant because those will affect students' achievements and promote learning. This condition is in line with Govindasamy [6], who emphasized that the consideration before using teaching materials in e-learning determines the implementation phase's success.

The researchers are interested in studying teachers' practices in using authentic e-materials in their e-learning courses from the background. The e-learning course scope covered the Learning Management System's use, and other computer instruction learning implemented both inside and outside the classroom or known as Blended Learning. The teachers' practices in using authentic e-materials focus on the types of authentic ematerials used by the teachers and their consideration in selecting and using authentic electronic materials. Thus, this study aims to answer the following research questions:
1. What kinds of authentic e-materials used by the English Language Education Department teachers in their e-learning courses?

2. What are the English Language Education Department teachers' considerations in selecting and using authentic e-materials in their elearning courses?

\section{LITERATURE REVIEW}

\subsection{Electronic Materials}

The material producers and curriculum developers are interested in adding computer-based and electronic materials in the syllabi since the technology has reformed how materials are created. Chapelle [7] said that the materials developers should be aware of CALL and try to consider it when producing the materials (as cited in Seidi, Dastnaee, \& Hedayati [8, p. 29]). The definition of electronic material is slightly similar to teaching materials. The difference between electronic materials and teaching materials lies in the term 'electronic' only. Landoni and Diaz [9] stated that electronic material is many products and prototypes to assist teaching and learning and has been extensively published electronically. Other experts, Krnel and Bajd [10], said that e-material is the program that guides the students through the learning. It implies that every kind of electronic material and supports teaching and learning is called electronic teaching material.

\subsection{Authentic E-Materials in E-learning}

Having a vivid understanding of the meaning of authentic provides a clear description of what authentic material is. Initially, the word authentic is used to describe every actual or natural interaction setting. Kramsch [11,p. 177] pointed out, "Authentic refers to the everyday language used; it is not intended for academic purposes". Thus, authentic material could be defined as some 'printed or spoken materials' that are not generally intended for language teaching [12]. Similarly, Wallace [13, p. 145] defined authentic materials as "real-life contents, which are not created for pedagogic purposes". In line with this, Adam, Stan, and Moanga [14] explained that authentic is real as any language, being used to convey a message in a given situational context. Hence, such resources are not likely to be given or created for teaching English to non-native speakers in particular.

Authentic material is defined as any materials produced to fulfill a purpose within a particular language community in "written and spoken materials containing real, unprocessed language, produced by a real speaker for a real audience and in a real situation" (Adam et al., [14]). If this authentic material is carried out and accessed 
utilizing a computer or other devices, especially over a network, it is known as the authentic electronic materials (authentic e-materials). Miller [15] pointed out that every resource converted into electronic form through electronic devices and is taken from the real situation is considered authentic e-materials. Besides, Harmer [16] asserted that authentic material in electronic is designed as it is valuable for language teaching and motivating students, presenting the real language, providing an authentic look of the culture, and serving as knowledge tools. It can be brief that authentic e-material refers to 'any learning materials that contain a real use of language created to fulfill a real language purpose and are accessible through any electronic devices'.

\subsection{The Kinds of Authentic E-Material in E- Learning}

Authentic materials are divided into three categories. eGyanKyosh [17] explained that electronic materials are broadly classified into three categories: audio, visual, and audiovisual materials. The three categories are described as follows.

\subsubsection{Audio}

This type of material mainly stimulates the learners' sense of hearing. Audio is related to hearing or sound. This type of material uses sound or sense of hearing for learning. Castro [18] explained that audio materials could be useful for studying history because students can hear recorded historical events such as political speech in an English Historian lesson. He further added that audio materials would perfectly suit for English language learning exercises. Examples of audio materials are CDs or audio recorded on the internet like flight attendant instruction, music, human voice, telephonic conversation, radio broadcast, and audiotapes.

\subsubsection{Visual}

The visual type of material involves a sense of vision. Visual is related to seeing or sight. eGyanKyosh [17] explained the examples of visual material in electronic are the e-book, non-projected two dimensional such as image or picture explaining a concept in .jpg or .png format charts, online poster, digital diagrams, digital graphs, photographs, cartoons, 3D visual, online advertisement, an online newspaper, online documents and clippings, cartoon, comic strips, and hologram

\subsubsection{Audiovisual}

The audiovisual type of materials involves a sense of hearing and vision. Audiovisual involves the use of recorded picture and sound or the equipment that produce them. eGyanKyosh [17] asserted that audiovisual is the projected aid that uses both auditory and visual senses to enhance learning. The audiovisual materials are motion picture film, video on the internet, video, slide and television.

\subsection{The Consideration to Use Authentic E- Materials in E-Learning}

There are several points of consideration the teachers need to know when using authentic e-materials in elearning. Department of Education Prince Edward Island [19] in its guideline stated that general considerations in using electronic materials including (1) the content of the materials and (2) the assessment of the materials. The content should be appropriate for the subject area and the age, emotional development, ability level, and learning styles. Besides, regarding the assessment, the assessment should be supportive of continuous learning by the individual. It should provide formative and summative assessments appropriate and relevant to the students' needs [19].

Some experts classified using authentic e-materials based on the categories of materials such as audio, visual, and audiovisual. The categories' primary consideration is how to select the appropriate materials and how to deliver the materials to students. eGyanKyosh [17] assumed that in audio materials, the selection of topic is essential. The verbal inputs are needed with the topic that will explain. The audio material can be exciting and useful when it integrates to chosen sound, music and special effects. The visual materials should provide authentic content knowledge; the content should be logical, coherent, and sequential; the language in the materials should be simple and understandable for every education level; the presentation of the content need to be conversational or verbal; the visual materials need to be a lot of activities and case, and the most important it must be relevant to the curriculum [17]. That way, eGyanKyosh explained that the audiovisual materials should be prepared for the learning process and related to the topic discussed.

\section{METHODS}

\subsection{Setting}

The researchers studied English Language Education Department in one private university in Indonesia. This setting was selected as this department offers some courses which integrate and expose its students to educational technology. Not only that, the teachers integrate e-learning in their courses with the use of authentic e-materials embedded in the LMS. This research was in the academic year 2018/2019 during the even semester. 


\subsection{Participants}

In deciding the number of participants, the researchers used purposive sampling in which the researchers chose the participants by their characteristics and experiences. Cohen, Manion, and Morrison [20] described that in purposive sampling, the researcher hand-pied the cases to be included in the sample based on their judgment of their particular characteristics being sought. The researchers set up two characteristics in selecting the participants. First, the participants were the English Language Education Department teachers with a minimum of two years of teaching experience. Second, the English teachers should have been teaching with elearning and using authentic materials for at least two semesters in a row. From the criteria, four teachers of the department were chosen as the participants of the study. Pseudonyms were used to maintain the anonymity of the participants' identities. Later, the participants were called Lucy, Isabelle, Albert, and Angela.

\subsection{Data Collection Instrument and Procedure}

The data were collected through the interview and observation of the e-learning LMS, including the learning materials being used. The interview was conducted to allow participants to share their ideas and their experiences using authentic material in e-learning. Cohen et al. [20] state that the interview enables the participant to discuss their interpretations of the topic and express how they regard the situation from their view. Openended questions were applied in this research because there was no limitation in participants' answers. The participants were allowed to share their opinions, ideas, and experiences. Cohen et al., [20] asserted that openended question has many advantages such as flexible, indepth clear any misunderstandings, and allow the researcher to build a correct opinion of what the participants believe.

An interview guideline was used as a tool to help the researchers organized the interview. In addition to it, an interview note was used to jot down important information from the participants' statements. The last tool was a voice recorder to record the interview to be transcribed for the data analysis. The interview was conducted in Bahasa Indonesia as both the researchers and the participants use it as their national languages. Besides, the researchers believed that using the national language allowed a better understanding of the context and more profound information from the participants.

Besides the interview, an observation was also conducted to explore the teachers' learning materials further. Whether the teachers truly integrated the use of authentic or created materials or the combination of both materials in their e-learning courses were quickly investigated through the observation. The observation was done by analyzing the LMS or the webpage in which the e-learning was conducted. The contents, such as the learning materials, the learning media, the learning activities conducted in the e-learning setting, were observed.

Before the observation, the researchers asked the teacher participants' permission to access their learning management system (LMS) at the end of the interview. The e-learning platforms used by the participants were varied. The most used platform was Moodle.org, the elearning faculty of the English Language Education Department, at www.learning.lang.umy.ac.id, which then migrated to https://myklass-lang.umy.ac.id/. The other platforms were Edmodo, Schoology, and Yammer. However, since 2018, all the teachers have been urged by the university to migrate to Moodle.org. After all the participants agreed, the researchers accessed the LMS to get more information about the teaching materials used in their e-learning courses. From the teacher participants' LMS, the researchers found several teaching materials in their e-learning as evidence.

\subsection{Data Analysis}

After collecting the data, the next step was to analyze the data to answer the research questions. The steps included transcribing the data, conducting member checking, and coding. The first step was transcribing each recorded interview from each participant. Creswell [21] stated that transcription is converting audiotape recording or field notes into text data. Then, member checking was done to look for the interview data's validity by showing the transcript results back to the participants. Creswell [21] explained that member checking is an activity in which the researcher asks the participant to check the transcription accuracy. The final step was coding, where the researchers identified similar findings and labeled them into categories. Cohen et al. [20] defined coding as breaking down segments of text data into smaller units and examining, comparing, conceptualizing, and categorizing it. The researchers performed the four coding processes, namely open coding, analytical coding, axial coding, and selective coding.

\section{FINDING AND DISCUSSION}

The research obtained the perceptions on the use of authentic e-materials in e-learning. The participants' perceptions vary into three points as emerged from the interview, in which they perceived such materials as important, useful, and yet challenging. The first participant, Lucy, stated that the authentic material in elearning was important. She acknowledged, "The use of authentic e-materials in e-learning is important because 
the authentic e-materials bring the real context of the language" (P1.21). The second participant, Isabella, believed that authenticity in e-learning was valuable as seen in the following excerpt, "The use of authentic material is useful and can support the learning" (P2.23). Albert, the third participant, respectively mentioned this idea. He mentioned, "What they [students] perceived will be what they produced, so if we use authentic materials, I believe it will be useful" (P3.23). Then, another perception was that the authentic material was challenging to use. Angela, the fourth participant, assumed that "The use of authentic materials in elearning was challenging as the purpose the authentic material is not for learning... It is more challenging because the authentic is only on the content" (P4.31).

\subsection{The Kinds of Authentic E-Materials Used in the E-learning Course}

Authentic material is being explained by Adam et al. [14] as any materials produced to fulfill a purpose within a real particular language, produced by a real speaker for a real audience and real situation. The participants mentioned some kinds of authentic materials in elearning, and the researchers classified them into three types. The types of the authentic e-materials used by the teacher-participants were audio, visual and audiovisual materials, and are elaborated below.

\subsubsection{Audio materials}

The findings of this study showed that audio material was the materials used by the teachers of the English Language Education Department. Audio materials use the sense of hearing. According to the Cambridge English dictionary [22], Audio is associated with sound. Castro [18] stated that Audio would perfectly suit language learning exercises. There were several authentic materials mentioned by the participants included in the audio material category. There were English songs and podcasts such as telephoning conversations.

\subsubsection{English Songs}

This authentic material stimulates the learner's sense of hearing. There are two participants acknowledged that songs as their authentic e-material in e-learning, Angela and Albert. Angela stated that she used the current song for teaching materials in the pre-teaching activities, depending on the topics being discussed. She stated, "I use current songs as one of the learning materials to discuss the topic" (P4.21). One of the songs was If I were a boy by Beyonce. She further mentioned, "So, for the example when I teach if clause, I use If I were a boy by Beyonce to practice its use" (P4.21). Another participant, Albert, expressed his experience in using a song as authentic material. He used the song in ice-breaking and teaching-learning activities. The song was chosen depends on the topic of his learning, and he embedded the song in the LMS. He explained, "If we want to find [the material] for the ice-breaking or I want to teach past simple, I can use the song" (P3.10). One of the songs he showed to the researchers titled Killing Me Softly by Fugees. He mentioned, "I played a song, the title is Killing Me Softly. I embedded the song in the LMS so that my students can access it" (P3.11).

This statement about using a song as authentic material is in line with Bokiev, Aralas, Ismail, \& Othman [23], who argued that song is a part of our language experience and can be a great value to foreign language teaching. Castro [18] mentioned that the example of audio materials is music and a human voice. Pappas [24] stated that using music is a powerful tool in the e-learning course to turn the course into an enjoyable and engaging e-learning course. Pappas added that using music in elearning can improve the knowledge, engage the sense and create an emotional connection. Thus, audio material like a song can be applied in e-learning to help the teacher create enjoyable e-learning courses. Teachers can embed song which are relevant to the lesson topic into the LMS.

\subsubsection{Podcasts}

This authentic material stimulates the sense of hearing. Both Albert and Angela revealed that Audio as their teaching material. Albert used Audio in the elearning course and is mostly taken from the internet. $\mathrm{He}$ expressed, "So, I know if we want to use audio, we can visit esl-lab.com or randals." (P3.6). He mentioned some of the websites for the Audio sources. The websites were americanenglish.state.gov, bbc.co.uk/learningenglish, learningenglish.voanews.com, and Podcast. $\mathrm{He}$ explained, "For the audio, we can visit americanenglish.state.gov, or BBC, or VOA, or podcast, and esl-lab.com" (P3.7). The audio contents depend on the topic of learning. He mentioned, "...for the example, the topic of our learning today is about tourism. I can take the material from there and here (showing his laptop) about hotel booking" (P3.9)

Another participant, Angela, used the Audio as an authentic material in her class. She admitted, "In this course, I use audio, video, and song" (P4.2). The content of the Audio was different depends on the topic of learning. She explained, "So for the example, we teach about making and responding to a formal telephoning. Later, I will find the Audio from Podcast or TED talks about telephoning. Another example is about an appointment with the doctor or announcement in the theather or airport". Angela mentioned that the source of the material was from the internet. She stated, "It is more surfing on the internet. For the link, I use TED talks and britishcouncil.org" (P4.10). 
Furthermore, this finding is in line with Brown [25], who stated that audio in e-learning could add humansense and provide an authoritative voice. Audio in elearning is useful for auditory learners as it makes sense to deliver through screen reader software [25]. Another expert, Castro [16], said that the examples of audio materials are CDs or audio recorder on the internet, telephonic conversation, and radio broadcast. Accordingly, the finding implies that language teachers can use audio materials to enhance their students' listening skills and also as an authentic input of the language that be embedded in the e-learning.

\subsubsection{Visual materials}

Based on this study's finding, the visual material was another type of authentic e-materials used in the elearning. This type of authentic e-material involves the sense of human vision [17]. Teachers presented the material visually displayed to engage students and interest them. It will stimulate their sense of sight. The authentic e-materials covered in the visual category based on the interview and the LMS observation were novels, journal articles, and pictures. The explanation is presented below.

\subsubsection{Novel}

This kind of visual aid is one of the books that present stories to the readers in different genres. Based on the researchers' data, the novel was used as one of Lucy's authentic materials in her e-learning course. She mentioned novels as tools for the assignment, then the researchers asked the teachers about the use of the novel, and she answered, "I used it [novel], to measure their competency, I provided some questions from some particular chapter or pages of the novel to observe their understanding towards the content. I also asked some grammatical points from the novel" (P1.7). The novel was selected and provided by Lucy on the LMS. The novel was used in her class related to the material and the learning objective being discussed, which was adjectives. By using novel, the students were asked to describe the people's characteristics and personalities of the novel. She explained, "One of the assessment is describing the characters that the students find from the novel" (P1.6)

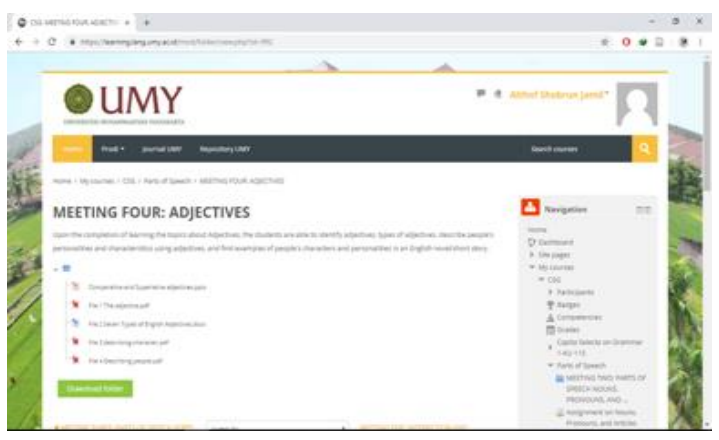

Figure 1. The use of novel in e-learning
The use of the novel as teaching material is in line with Oda and Khaz'al [26]. They explained that the novel helped the language learners to stimulate activities in learning a language. The novel had an essential role in developing language skills because of the range and variety of English presented in real and concrete writing. In addition, novel is authentice. In e-learning, the novel can be uploaded to the LMS by the ELED teachesr, and they can use it according to the needs. Thus, novel can be used as one of the authentic learning e-materials in the elearning and has an essential role in developing language skills.

\subsubsection{Journal article}

Journal articles are articles written by experts or the professionals in their fields. Based on this research's finding, authentic material was used by two participants, Angela and Isabella. Isabella said that she worked with another teacher to use thirteen journal articles representing their course topic. She mentioned, "We take thirteen journal articles representing our topic of learning, especially related to the Education Technology". Another participant, Angela, used many articles, research articles and manuscripts. She stated, "Depend on courses, so if [I teach] this course [Innovative Technology course], I use some research articles or research manuscript" (P4.1). She added that the topic of the articles was about education and educational technology. She further stated, "In this course [Innovative Technology course], because the focus of the learning is to expose students to some ideas of current research on Educational Technology, my colleague and I used some reseach manuscripts as the teaching materials." (P4.3). Then she stated, "For this course, the tòpic of the articles being used are related to Education Technology" (P4.4).

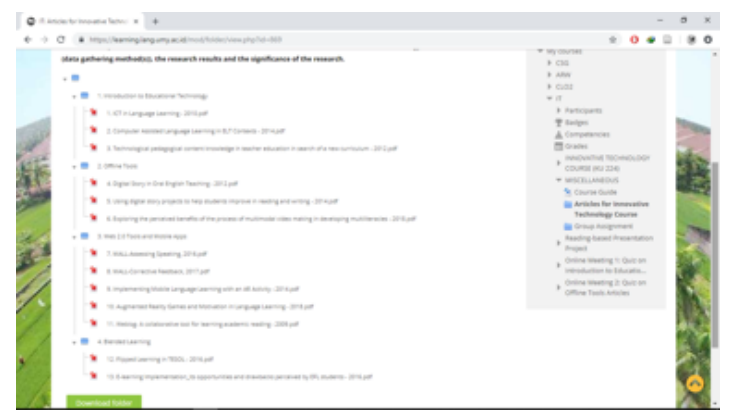

Figure 2. List of the journal articles in e-learning

The statement above is in line with Ruiz and García [27], reporting that researchers' journal articles to inform specialists of the latest of their specific field of study were fascinating sources of authentic material. The teachers would choose the journal's part, such as the section, diagram, paragraph, and material in terms of their relevance and interest [27]. Teachers in ELED used 
journal articles as the authentic e-materials in their teaching practices.

\subsubsection{Picture or Infographic}

This authentic material stimulates a sense of vision. Based on the study's finding, Isabella, Albert, and Angela mentioned that they used pictures as a teaching material. Isabella told story that pictures were used in her course, especially when she tested or examined her students' understanding towards the lesson. She attached pictures in Kahoot! for instance. She answered the question about is there any attached file to support Kahoot games, and she replied, "Yes, it is a picture"(P2.7). Isabella explained she used two kinds of pictures. It was an original picture and text in the form of a picture. She explained, "In elearning, we can provide a diferent variation of picture, can be image or infographic."

Other participants, Albert and Angela, stated that they also used picture as their teaching material. Albert explained that he attached pictures to Padlet then there was a discussion section with the picture as the topic. He stated, "We can insert a picture to Padlet" (P3.5). He further stated, "If picture is used in my online class, the activity is I ask my students to write their thought about the picture or image, then discuss it in an online forum" (P3.19). Likewise Albert, Angela used a picture for the topic of discussion. She added that she also used a picture as the topic of bibliographic text or descriptive text. She mentioned, "I also use photo" (P4.5), then she added that, "...So they discuss about the picture and create the text. It can be bibliography text or descriptive text about the picture" (P4.20). The topic of the picture depends on the topic of the lesson. Both Albert and Angela used famous people and famous places pictures as a teaching material. Albert and Angela said, "The picture is about famous people and famous places" (P4.20)

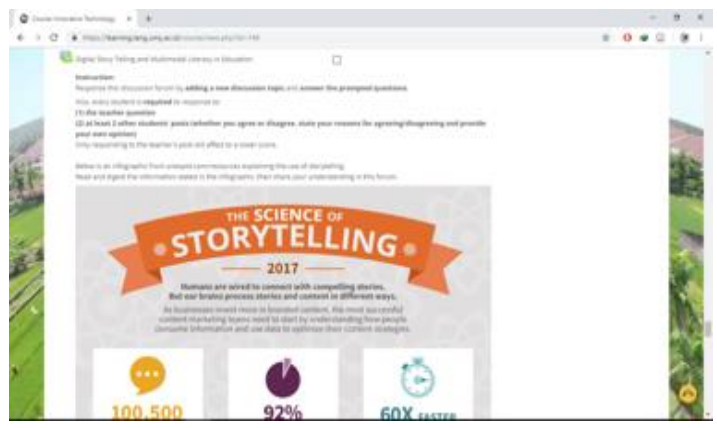

Figure 3. The use of picture or Infographic in teaching e-learning

This statement of using the picture/image/photo/ infographic as an authentic e-material in e-learning reflects what Harris and Caviglioli (2003) believes that visual tools are powerful aid that builds up knowledge (as cited in Krčelić \& Matijević [28]). Krčelić and Matijević [28] said that there are several visual tools such as pictures, posters, photos, icons, illustration, figure, presentation, symbol, and mind maps. Krčelić and Matijević [28] added that the use of visual tools in the classroom needs to be carefully planned and have a clear purpose by the teacher. It is implied that picture is as one of the authentic e-materials which is relevant to be used Language teachers.

\subsubsection{Audiovisual Materials or Multimedia}

This study revelead that other than audio and visual materials, audiovisual materials or multimèdia was also integrated into language teaching and learning. According to the Cambridge English dictionary [22], Audiovisual involves the recorded picture and sound. In addition, eGyanKyosh [17] argued that audiovisual enhances learning through both the audio and visual senses. The participants mentioned several authentic ematerials included in the audiovisual category. There were videos and movies. The explanation is below.

\subsubsection{Video}

This authentic material is commonly used in elearning, one of which is video. Video is the type of material that involves a sense of vision and hearing. The finding of this study uncovers the use of vídeo as an authentic e-learning material by three participants. Isabella mentioned that she used videos about blogging and some other applications/softwares that suport language learning she discussed in her course. She mentioned, "... Watching video about blogging" (P2.6). Another participant, Angela, also used video as a teaching material embedded in the e-learning. She explained that she used video in speaking and listening class, "In this course, I use audio, video, and song" (P4.2). The content of the video depends on the topic of course. She provides a short movie, or cooking vídeo, and an MC video. She mentioned, "Vídeo as the material is used and in accordance with the lessons" (P4.24). Then, other participant, Albert, also mentioned he used video as his teaching material. He stated, "I play the video" (P3.1). He added, "It is about describing people" (P3.2). The content of the video was varied depending on the topic of the course. He also mentioned short movie and movie footage as the content of his video. Mostly he got the video from the internet. He explained, "...for the video, I took from YouTube, but not only YouTube, sometimes from britishcouncil.org, and there are also lots of good and interesting videos" (P3.13). 


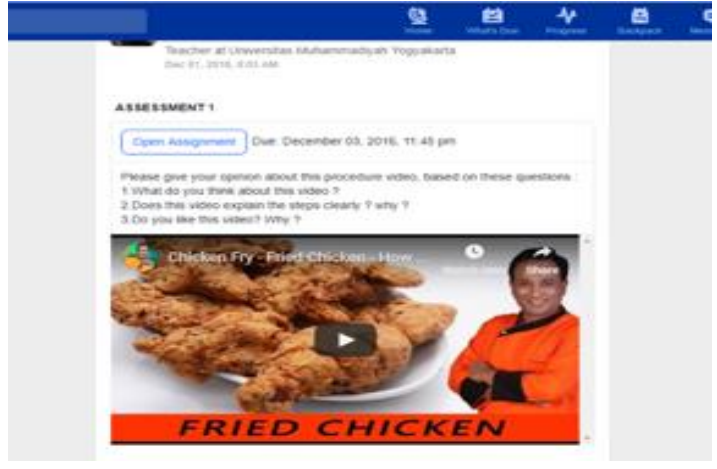

Figure 4. The use of video in e-learning

This statement about using vídeo as an authentic material is in line with eGyanKyosh (2017). Audiovisual material facilitates language learning, including vídeo. eGyanKyosh (2017) mentioned that the audiovisual materials cover video on the internet, movie, and motion pictures. In addition, Pongsapan [29] argued that the audiovisual materials have a significant impact in learning as long as they are used appropriately and selected carefully. It can be said that teachers can use video as the authentic e-material for language learning with a careful selection and consideration.

\subsubsection{Movie}

A movie is a story recorded by the camera, and it is shown in a theater or television named movie. Based on the findings, there were two participants used movies as their authentic materials in e-learning, Albert, used video mostly as the input for his students in speaking and listening class. He said, "The video is as an exposure to the target language" (P3.16). The content of the video was movie footage or short movies about the topic of learning. He explained, "So for example, we discuss describing people, the first thing that I did was finding the movie footage about describing people" (P3.16). Angela also used a movie as her teaching materials in elearning. She stated, "I use film or short movies which won an award, or award-winning movies" (P4.23). The content of the movie depends on the topic of the course. She gave the example of the video which is a short movie that won an award. She also mentioned the duration of the short movie she selected, "The maximal duration of the movies is around 10 minutes" (P4.23).

The statement above is in line with Pongsapan [29]. Videos such as movies and TV programs are made for a native speaker, so video provides authentic language input. Kabooha [30] also stated that the use of movies in e-learning could draw in the audience, hold the attention for learning duration, and make the learning memorable. The movie is made for native and contains much input for the people as entertainment and can be used for academic courses, too, as the authentic material. Thus, movies can be used as an authentic material in language teaching.

\subsection{The Teachers' Consideration in Integrating Authentic E-Material in E-learning}

There were some considerations in using authentic material in e-learning. The participants mentioned different opinions about their considerations to use authentic material in e-learning. The teachers' considerations using authentic material in e-learning were varied. The considerations were divided into material consideration, contents consideration, and time to prepare from the participants' answers. It is described in the paragraph below.

\subsubsection{Material consideration}

This part mainly talks about considering how to find and the preparation before using the authentic material. Based on the finding, there are seven categories in preferences consideration. There are the material display, the material function, the material, effectiveness, and affordable material. It is presented in the paragraph below.

\subsubsection{The material displays}

Based on this research's finding, participant one, Lucy, considered the face validity of authentic material. She said, "First consideration is from (think) basic face validity" (P1.16). Lucy further explained that the appearance of the material could increase the students' interest. She added, "...for the example if we are looking the article for the first semester, the appearance must be fun, then the writing is not too small, and the writing format must be good" (P1.16).

According to Ahmed [31], aesthetic involvement stimulates brain activities. The appearance of the material can interest the learners. As McGrath (2013) stated, the material must be visually appealing (as cited in Ahmed, 2017). Chambers [32] stated that the aesthetic of material in e-learning balances the exciting design and the content material. The display brought the learning from point to the point of the material; the display must not be too distracting but lighten the enthusiasm. So, based on the statement and theory, the material's face validity can attract the learners. This point is also included as one of the teachers' considerations when using authentic materials [33].

\subsubsection{The material functions}

Regarding the finding of this research, one participant of this study stated that he considered the material's function. The statement above stated that the appearance of the material was an essential consideration. However, Albert had a different opinion about consideration. He specified, "Considered the function; it means that the important was the lesson delivered it should not have to be aesthetic" (P3.27). He preferred to use material based 
on the function and considered the core of the lesson delivered clearly without thinking about the appearance or the aesthetic of the material.

\subsubsection{The material effectiveness}

Based on the study, material effectiveness becomes one of the considerations in teacher preference. It was mentioned by participant three, Albert. Albert considered the effectiveness and practicality of the material. The link he used was useful because it saved his time getting good material in a limited time. Albert stated, "If the considerations in my preference are it is effective and practicality" (P3.25). He explained most of the teaching material he used from the internet, and it saved his time rather than created the material by himself. The source of the material provided complete material to teach the topic being discussed. He explained, "Why I use that link is because everything was complete" (P3.22).

\subsubsection{The material sizes}

When talking about authentic material used in elearning, it closely related to digital material. Many of the teachers used digital material like audio and video from the internet. They should consider the size of the material to make it displayed. Participant four, Angela, stated that she considered the size of the material. She mentioned, "Then the size of the file. If the size is small, I will upload it. But if the size is big, I only give the link to the students" (P4.17).

\subsubsection{The material cost}

Based on this research finding, another consideration was the affordable material to be used in e-learning. Participant four, Angela, mentioned that she considered the costless material to get. She preferred the free material to get rather than spending money on the material. She explained, "Whether or not it is free, why should I spend my money if it is free and usable from the website" (P4.29).

This statement is in line with Berardo [33], who said that having unlimited internet access in looking for materials costs nothing, only time from an economic point of view. Berardo [33] added that trying to obtain authentic material aboard can be expensive. The cost of the magazine can up 3-4 times higher. Thus, one of the considerations was the cost of the materials. Teachers prefer to get free authentic material from the internet instead of spending their money to buy authentic material abroad.

\subsubsection{Content consideration}

The material's content impacts the teaching-learning process, where the students can learn something and stimulate their understanding of the lesson. According to Ahmed [31], authenticity means that "Content-based where the language learning is not those that serve a nonpedagogical purpose with another community of users but rather those that particular group engage with and create discourse around for meaningful purposes" (p186). Thus, when teachers use authentic material in learning, it was related to the content, making sense that the teachers in this study consider the material's content. There were four categories from the content consideration. There was the convenient material, the material's level, the clarity of the material, the material's culture, and its length. The explanations are presented below.

\subsubsection{The appropriateness of the material}

The study found that the materials' use should be considered from the material's content. The appropriateness with the syllabus and the students' level was essential to consider. The authentic materials should be in line with the syllabus and the students' level. Both aspects are described below.

\subsection{The syllabus}

Based on this study's finding, participant one, Lucy, stated that she considered the relevant, authentic material to use in e-learning. According to participant one, Lucy chose authentic material where it was relevant to the syllabus. She stated, "Is the material that I gave are relevant with the RPS or syllabus" (P1.18). The same idea mentioned by participant two, Isabella, where the material's content must be representing the topic being delivered with the learning topic. She explained, "Sometimes, I will see the content of the materials, is the content representing the topic being discussed?" (P2.16).

According to Tomlinson [34], good authentic material is a material that the learners should perceive learning materials relevant and useful. The material's relevance was essential because the relevant material to the topic helps the teachers achieve the lesson's objective (as cited in Ahmed [31]). Thus, authentic material must be relevant to the syllabus and represented the topic being delivered.

\subsection{The students' level}

Based on this study's finding, using authentic material in e-learning should be following the students' level. Participant one said that she considered the level of the material at the same level as the students. She explained, "The level of the material must be adjusted with the students' mastery" (P1.4). If the material follows the students, they will quickly understand the lesson from the 
authentic material. The same idea was also mentioned by the third participant saying that he considered the students' level when using one material. He explained, "If the consideration in term of the students is their proficiency level" (P3.24). Another participant, Angela, explained that teachers also need to consider the material's difficulty before using it in e-learning. Angela said, "The first consideration is the students understand or not with the content of the material" (P4.25). The level of difficulty of the material was her consideration in using authentic material in e-learning. Similar to Angela, Isabella also considered the level of the difficulties of the article. The article was used as one of the authentic materials in Isabella's class. She said, "For the article, we added the level of difficulties because we never choose the article that for us it is difficult to understand, especially if it is given to the students" (P2.19).

The material level consideration statements are in line with a blog by the TEFL academy [35]. When finding the materials, some authentic materials are a naturally higher level of English. According to Tomlinson (1998), the learner should feel at ease with the materials. The learner should feel that the material builds their confidence and is useful. The students' consideration was at the level of the materials. Thus, the materials' level of difficulties was one of the teacher's considerations in teaching e-learning.

\subsubsection{The clarity of the material}

Based on the study's findings, the material's clarity is one of the teacher's considerations. Isabella explained that the content must be represented the lesson's topic to be delivered. She said, "Next is clarity" (P2.18). Isabella gave an example from an authentic material presented person talking about something. She had to make sure the person talked clearly to understand what the person was speaking and added superb authentic material, but it was hard to understand. There was terrible clarity. She would not use it. She said, "Nest is clarity, it means that what is he or she said is clear or not and I should consider the students understand with the author or the creator said" (P2.18).

This statement above is in line with eGyanKyosh [17], reporting that the authentic materials selection topic is essential. eGyanKyosh [17] added that the visual material's language should be simple and understandable for every education level, and the language used should be clear enough. Thus, the clarity of the content was one of the considerations by the teachers.

\subsubsection{The culture of the material}

Authentic materials are formed from various languages, accents, habits, behavior, religion, and cultural matters. Based on this study's findings, English language teachers need to consider the content's culture when using authentic material. Authentic material brings the real context of the native's culture and possibly different from the other countries. The third participant considered the culture of the content when using authentic material in e-learning. He said, "Sometimes the consideration comes from the culture" (P3.23). He explained that when hearing Audio or seeing a video or worksheet, it appeared to be public places such as a cathedral, church, temple but mosque was not existing. He further explained, "For the example, if we heard audio or watched a video, it showed the place for public places. The public places are the cathedral, church, temple, and it doesn't mention the mosque as the public places. As the teacher, we should explain to the student if it is natural" (P3.23).

According to Mishan [36], using authentic material to facilitate language learning needs to adapt to culture because it enables the students' comprehension of the language they learn and their image of the society where it was spoken. The culture was one of the considerations by the teacher. The authentic material may contain different culture with English for second language and English for foreign language students.

\subsubsection{The duration of the material}

Regarding the study's finding, one of the participants mentioned the material's duration as a consideration. Participant four, Angela, considered the duration of the video material when teaching e-learning. She said, "The second consideration is the time because this is an online course. It means that we cannot choose the long one [duration]. For example, if we use a movie, the duration is around 10 minutes" (P4.26).

\subsubsection{The length of the material}

When using authentic material considering the length, the participants specified to the article. Participant two said that she considered the article's length. She would use articles under 10 pages or 11 and 12 pages maximal. She said, "The length of the article is also considered. So, we try to find the article under 10 pages"(P2.20). Like participant two, participant four, Angela said that she considered the length of the material. She mentioned, "It is more to length" (P4.30). She preferred to use the fewest pages. She explained, "Then if I look for the article on the internet, there will be the article in 15 pages, 12 pages, or 20 pages. I will prefer to use 12 pages." (P4.30)

\subsubsection{Time preparation consideration}

Based on this research finding, time was one of the considerations that showed up in the interview. There were two participants mentioning time as their consideration in choosing authentic material. They were participant one and participant four. Participant one, Lucy, considered the time to find the material. She stated that the materials needed were available on the internet. 
It was only the availability of the teacher to find the material. She stated, "The materials that we need are already available on the internet, just we have time or not to find the materials" (P1.19). Another participant, Angela, mentioned time as her consideration. Angela considered the flexibility in time to find, prepare and do the material. She expressed, "So it [the materials] is flexible or not from the time for me. It means finding, preparing, and doing the material in e-learning need time" (P4.29). So, time flexibility means that the material can be used anytime without needing many times of preparation. Teachers can get material from online sources.

\section{CONCLUSION AND IMPLICATION}

\subsection{Conclusion}

Based on the findings, the authentic e-materials are divided into three categories that the teachers used in elearning. The categories are audio, visual, ad audiovisual. There are several types of authentic e-materials included in each category. For audio material, the authentic materials used were song and recorded-audio, such as telephoning conversation, and announcement. For the visual material, the authentic e-materials were pictures, novels, e-books, and journal articles. While for the audiovisual material, YouTube vídeo or award-winning short movies were used and embedded inside the LMS..

The second result of this study is the teachers' consideration in using authentic e-materials in e-learning. There are three significant findings in this section. The first consideration is on the material, including the material display, the material function, the material effectiveness, the material's size, and the affordable material. The second consideration comes from content, including the appropriateness of the materials, the clarity of the materials, the culture of the materials, the duration of the materials, and the length of the materials. The third consideration is related to the time preparation.

To sum up, language teachers can use myriad authentic e-materials embedded in their e-learning, such as novels, e-book, songs, and pictures. The use of authentic e-material is practical and engaging. For some purposes, authentic materials are useful and suitable for language learning. However, teachers need to be careful and selective in choosing the authentic e-material. Not every authentic e-material suits the learning objective and the learning context. As time goes by, the technology will develop, and it brings a chance for the teacher to improve their teaching and learning skills. The teacher can combine the use of authentic e-materials with the current educational Technology.

\subsection{Implication}

\subsubsection{The teachers}

Integrating authentic e-materials can be significant to enhance and vary the teaching and learning materials. Teachers, especialy language teachers, should always consider several aspects before using authentic ematerials and integrate them in the e-learning, such as content, culture, and time. Teachers are also suggested to combine and use current EduTech in their e-learning courses. They are also expected to join workshop or training about integrating technology to enrich their knowledge and skill. Finally, teachers are suggested to spend their time finding the appropriate authentic ematerials, preparing the authentic e-material for elearning, and reflecting or evaluating the lessons which integrate authentic e-materials.

\subsubsection{The University Stakeholders}

The study's findings imply and recommend the institution to provide sufficient facilities for the students and the teachers when implementing e-learning in English Language Education Department. The facilities include a good internet connection, a supported computer lab computer, and continuous training and workshop about the technology and material design integrating technology for its faculty members. These facilities are believed to better support and facilitate the teachinglearning activities.

\section{REFERENCES}

[1] T. Anderson, The Theory and Practice of Online Learning, 2nd Edition ed., Canada: AU Press, Athabasca University, 2008.

[2] H. Kanuka, "Understanding e-learning technologies-inpractice through philosophies-in-practice," in The Theory and Practice of Online Learning, Canada, AU Press, Athabasca University, 2008, pp. 91-120.

[3] A. S. Yucel, "E-Leaning Approach in Teacher Training," Turkish Online Journal of Distance Education, vol. 7, no. 11, pp. 1-8, 2006.

[4] Djono, "The Development of Historical Instruction/Teaching Material in Senior High Schools Based on Local History with SOI Approach," DIJE, vol. 1, pp. 47-57, 2013.

[5] A. Rossett, "Walking in the night and thinking about elearning," in The ASTD e-learning handbook, New York, McGraw-Hill, 2002, pp. 3-18.

[6] T. Govindasamy, "Successful implementation of elearning pedagogical considerations," The Internet and Higher Education, vol. 4, pp. 287-299, 2001. 
[7] R. Surovov and C. Chapelle, "Computer-Assisted Language Learning Effectiveness Research.," in The Encyclopedia of Applied Linguistics, 2020.

[8] A. Seidi, T. M. Dastnaee and S. Hedayati, "Developing Electronic Materials for Language Curriculum Development: Issues, Obstacles, and Implications," ICT \& Innovations in Education' International Electronic Journal, vol. 2, no. 1, pp. 26-36, 2014.

[12] B. Tomlinson, "Glossary of basic terms for materials development in language teaching.," in Materials Development in Language Teaching (2nd Ed.), Cambridge, Cambridge University Press, 2011, pp. viiixiv.

[13] C. Wallace, Reading, Oxford: O.U.P, 1992.

[14] S. L. Adam, R. S. Stan and A. S. Moanga, "Authentic language teaching materials-advantages and challanges," Bulletin UASVM Horticulture, vol. 68, no. 2, pp. 353$354,2011$.

[15] L. Miller, "Developing listening skills with authentic materials.," ESL Magazine, vol. 6, no. 2, pp. 16-18, 2003.

[16] J. Harmer, The Practice of English Language Teaching, Harlow: Longman, 2007.

[17] eGyanKyosh, Unit 7 teaching learning materials, New Delhi: IGNOU, 2017

[18] P. G. Castro, "Design of English Language Teaching Materials," Universidad de La Laguna, Spain, 2015.

[19] P. E. I. Department of Education, Guidelines for the Evaluation and Selection of Learning Resources, Charlottetown: Prince Edward Island, 2008.

[20] L. Cohen, L. Manion and K. Morrison, Research Methods in Eduction, London: Routledge, 2011.

[21] J. W. Creswell, Educational Research: Planning conducting, and evaluating quantitative and qualitative research, 4th Edition ed., USA: Boston: Pearson, 2012.

[22] Cambridge business English dictionary., 6th ed., Cambridge: Cambridge University Press., 2011.

[23] D. Bokiev, U. Bokiev, D. Aralas, L. Ismail and M. Othman, "Utilizing Music and Songs to Promote Student Engagement in ESL Classroom," International Journal of Academic Research in Business and Social Sciences, vol. 8, no. 12 , pp. 314-332, 2018.

[24] C. Pappas, "The use of music in eLearning: 4 tips for elearning professionals," 5 January 2016. [Online]. Available: https://elearningindustry.com/use-musicelearning-4-tips-elearning-professionals. [Accessed 5 December 2018].

[25] E. Brown, "The use of audio in elearning," 31 October $2016 . \quad$ [Online]. Available:
[9] M. Landoni and P. Diaz, "E-education: Design and evaluation for teaching and learning," Journal of Digital Information, vol. 3, no. 4, 2003.

[10] D. Krnel and B. Bajd, "Learning and E-materials," Acta Didactica Napocensia, vol. 2, no. 1, p. 98, 2009.

[11] C. J. Kramsch, Context and Culture in Language Teaching, Oxford: Oxford University Press, 1993.

https://leolearning.com/2016/10/the-use-of-audio-inelearning/. [Accessed 5 December 2018].

[26] O. Oda and K. Khaz'a, "COba coba coba," p. 2009.

[27] L. P. Ruiz and C. S. García, "Benefits of using authentic materials in an EST class," Journal of English Philology, vol. 25, no. 4, pp. 183-192, 2003

[28] P. Krčelić and A. S. A. Matijević, "A picture and a thousand words: Visual tools in ELT," The International Language Conference on the Importance of Learning Professional Foreign Languages for Communication between Cultures, pp. 110-114, 2015.

[29] Pongsapan, "Material in Foreign Language Teaching Classroom," Jurnal Keguruan dan Ilmu Pendidikan, vol 2, no. 3, pp. 285-292, 2013.

[30] R. Kabooha, "Using Movies in EFL Classrooms: A Study Conducted at the English Language Institute (ELI), King Abdul-Aziz University.," English Language Teaching, vol. 9, no. 3, pp. 248-257, 2016.

[31] S. Ahmed, "Authentic ELT materials in the language classroom: An overview," Journal of Applied Linguistic and Language Research, vol. 4, no. 2, 2017.

[32] K. Chambers, "Five considerations when designing engaging elearning courses," 24 August 2015. [Online]. Available:

https://www.learningsolutionsmag.com/articles/1775/fiv e-considerations-when-designing-engaging-elearningcourses. [Accessed 5 December 2018].

[33] S. A. Berardo, "The use of authentic materials in the teaching of reading," The Reading Matrix, vol. 6, no. 2 , pp. 60-69, 2006.

[34] B. Tomlinson, "Glossary of basic terms for materials development in language teaching.," in Materials Development in Language Teaching, Cambridge, Cambridge University Press, 1999, pp. viii-xiv.

[35] "How to choose authentic materials for the EFL classroom," November 2017. [Online]. Available: https://www.theteflacademy.com/blog/2017/11/how-tochoose-authentic-materials-for-the-efl-classroom/. [Accessed 13 November 2018].

[36] F. Mishan, Designing Authenticity into Language Learning Materials, Bristol: Intellect Books, 2005. 